\title{
DEVELOPING A BASE INDEX FOR ENVIRONMENTAL ASSESSMENT OF COASTAL RESORT PROJECTS ALONG RED SEA COAST OF THE CITY OF JEDDAH
}

\author{
Mohammad Abdul Rahman Kattan ${ }^{+}$, Mahmoud A. Taha ${ }^{\star}$ \\ and Abdullah Mostafa Mohorjy \\ + Project Director for Girls Faculties, King Abdul Aziz University, \\ Kingdom of Saudi Arabia \\ * Associate Professor, Civil Engineering Department, Construction \\ Management Program, King Abdul Aziz University, on leave from \\ Structural Engineering Department, Cairo University, Egypt. \\ ** Professor of Water Resources \& Environmental Engineering, King \\ Abdul Aziz University, Kingdom of Saudi Arabia
}

\section{(Received May 7, 2011 Accepted June 2, 2011)}

The decision for approving Environmental Impact Assessment (EIA) is complex due to data uncertainty related to inability to collect the required data sets on existing baseline conditions. The current practice of EIA implementation in the city of Jeddah, Kingdom of Saudi Arabia (KSA), is conducted without a base index for the evaluation of project alternatives and proposals.

This paper attempts to propose a systematic procedure used for developing a base index for the city of Jeddah that employs the expertise of a domain expert in the field of EIA for coastal resort projects to operate the fuzzy logic approach. This technique handles uncertainty and offers a practical solution to the evaluation of environmental impacts that express the quantitative threshold and represent qualitative values inherited in EIA decision process. In this paper, 30 input variables and 10 indicators are considered in the assessment of the existing baseline conditions for the city of Jeddah.

KEYWORDS: Environmental Impact Assessment (EIA), Baseline Conditions, Uncertainty, Fuzzy Logic, Quantitative Impacts, Qualitative Impacts.

\section{I - INTRODUCTION}

The government of the Kingdom of Saudi Arabia (KSA) represented by the General Presidency of Meteorology and Environment (PME) issued in 2001 the General Environmental Regulations that necessitates the implementation of an Environmental Impact Assessment (EIA) studies at the feasibility stage of projects, which might cause adverse effects on environment (PME 2003). One type of such projects is coastal resort projects developed directly along seacoast. Before the issuance of the Saudi environmental regulations, uncontrolled coastal resort development projects along the Red Sea coast of Jeddah city had led to severe deterioration of some unique natural resources (PERSGA 1995). A recent marine survey conducted in 2004 on the coral reef communities of the Red Sea revealed that about $70 \%$ were destroyed and the remaining 
were either defected or exposed to destruction (AL-Kenani 2008). However, local EIA practitioners are claiming that the current practice of EIA implementation after the issuance of the environmental rules and regulations is still weak and there are problems that must be addressed to improve the process. Such underperformance of EIA process has been attributed to the following reasons:

1. Non-awareness of community members to the standard practice of EIA being detailed in the Saudi environmental laws and regulations.

2. Data uncertainty related to inability to collect the required data sets on existing baseline conditions in the city of Jeddah and hence no base index for the evaluation and comparison of project alternatives and proposals.

3. The decision for approving EIA study is complex because the evaluation of impact significance is both quantitative which is expressed as a regulatory threshold and qualitative that represents subjective values. In EIA, these values are usually expressed as linguistic terms that are inherently ambiguous or fuzzy.

EIA is a decision aid tool defined as the study of the effects of a proposed action on the environment either positive or negative. Therefore, depending on the effects of scale of the proposed action, an EIA may include studies of the weather, flora, fauna, soil erosion, human health, urban migration, or employment, that is to say, of all physical, biological, social, economic and other impacts (Ahmad and Sammy 1985). According to Liu et al. (2007), EIA process follows sequence of steps including screening, scoping, studying baseline conditions, identifying potential impacts, predicting impacts characteristics and evaluating their significance. According to Shepard (2005), screening determines whether EIA is required for a given project or not. Scoping aims at identifying the priority issues that need to be addressed during EIA. A baseline condition study is a standard by which the future conditions of project alternatives are compared. Historically, several methods are used to identify impacts according to baseline condition including ad hoc, overlay, checklist, matrix and networks methods. Impact prediction analyses all changes likely to occur because of the project construction based on several characteristics including importance, magnitude, mitigation and tangibility. Once an impact has been forecasted, it is necessary to evaluate the impact significance on environment. Consequently, decision makers can decide whether to accept the proposal or not.

There is a number of Decision techniques proposed in the literature for the approval of EIA studies. Among them are the Multi Attribute Utility Theory (MAUT) (Keeney and Robilliard 1976), Analytical Hierarchy Process (AHP) (Tsamboulas and Mikroudis 2000), Neural Networks (NN) (Shepard 2005) and Fuzzy Logic (FL) (Boclin and Mello 2006). It has been found that FL provides best decision technique for EIA since it offers a practical solution to the evaluation of environmental impacts that express the quantitative threshold and represent qualitative values inherited in EIA decision process. Therefore, the main objective of this paper is to develop a base index for environmental assessment of coastal resort projects along Red Sea coast of the city of Jeddah using fuzzy logic for the evaluation and comparison of project alternatives and proposals. 


\section{II - METHODOLOGY}

The EIA developed method to achieve research objective consists of three steps: 1) Impact Identification, (2) Knowledge Acquisition, and (3) Implementation.

\section{II-1- Impacts Identification}

To start modeling EIA decision component, environmental impacts of coastal resort projects had to be identified. Such identification requires an extensive literature review on the published national and international case studies to identify the environmental impact due to the construction and operation of coastal resort projects. The collected impacts from literature have to be investigated by a group of local practitioners who have the knowledge and expertise to verify and develop the required environmental impacts that shall be used as the input variables for EIA decision component of the research study. Accordingly, a survey questionnaire shall be conducted to obtain an industry feedback from a panel of practitioners working in different government agencies and private sector consulting offices at the city of Jeddah. The Delphi technique had been used to verify impacts collected from literature and to add new ones if necessary. The survey consisted of two major phases. The first is the pre study phase consisted of three steps including formation of contact network, design of Delphi questionnaire, and pilot interviews to refine questionnaire format design. The second phase is the Delphi iterations consisted of three rounds that had been concluded with the final list of most significant environmental impacts due to the construction and operation of coastal resort projects in the city of Jeddah. A list of 24 impacts was collected. Two of them (Water and Air quality) are quantitative and have regulatory thresholds in the Saudi environmental law. A domain expert in the field of EIA was consulted to define the parameters of air and water quality that should be included in the environmental assessment. The parameters selected by the domain expert for Air quality were Sulphur Dioxide $\left(\mathrm{SO}_{2}\right)$, Nitrogen Dioxide $\left(\mathrm{NO}_{2}\right)$, Particulate Matter $\left(\mathrm{PM}_{10}\right)$ and Carbon Monoxide $(\mathrm{CO})$. The parameters for water quality were Dissolved Oxygen (DO), Total Suspended Solids (TSS), Ammonia Nitrogen $\left(\mathrm{NH}_{3}-\mathrm{N}\right)$ and Biochemical Oxygen Demand (BOD). The domain expert had been consulted for the grouping of impacts to represent the environmental condition. One of the best ways to find how the decision can be detailed is to arrange these individual variables according to a top down decision tree structured in a hierarchical form as suggested by Boclin and Mello (2006), and Liu et al. (2007). At each node, a group of input variables is aggregated to a new one. This makes Four layers of abstraction. The first layer contains the individual impacts or variables concluded from Delphi survey which are Permits Approval, Law Enforcement, Health and Safety, Public Attitude, Ethics, Quality of life, Design Compatibility, Services Provision, Aesthetics, Waste Collection, Coral Reefs, Coastal Fisheries, Mangroves, Endangered Species (Aquatic Life), Vegetation Cover, Endangered Species (Terrestrial Life), Noise Levels, Liquid Chemical Residue, Coastal Erosion, Land Values, Revenues, Employment, BOD, DO, $\mathrm{NH}_{3}-\mathrm{N}, \mathrm{TSS}, \mathrm{SO}_{2}$, $\mathrm{NO}_{2}, \mathrm{PM}_{10}$, and $\mathrm{CO}$. Every group of variables constitute several sub groups including Institutional, Social, Economic, Technical, Aquatic Life, Terrestrial Life, Air quality, Water Quality, Soil and Noise. Subsequently, sub groups constitute higher order groups of Human, Ecology, and Physical from which the Total Environmental 
Condition is concluded. All sub groups and groups are considered as the indicators in which their resulting values represent the magnitude of relative severity. The higher the magnitudes, the change to each indicator condition tends to be Bad and vice versa. Figure (1) represents the entire structure of the Impact Decision Tree (IDT) for Jeddah case study.

\section{II-2- Knowledge Acquisition}

The technique used to estimate the possible changes at each output variable is Fuzzy Logic. This technique offers a practical solution to the evaluation of environmental impacts that express the quantitative threshold and represent qualitative values inherited in EIA decision component. After defining the input variables through Delphi technique, the input values for each individual input variable is estimated by quantifying the impact evaluation of significance. According to UNEP (2002), impact evaluation is a result of multiplying impact importance by impact magnitude. The technique used to determine each impact importance weight is the Pair wise Comparison method. This method involves the comparison of each variable to every other variable on a pair wise basis. In each pair, a value of (l) is assigned to the variable considered to be more important, and a value of (0) to the other variable (Mohorjy 1997). In cases of equal importance, every variable takes the value of (0.5). A "dummy variable" is included to preclude the net assignment of (0) value to any basic variable in the process of each paired comparisons. The implementation of this technique on this research study is conducted for every group of variables, which constitute a sub group. For example, permits approval and law enforcement constitutes the institutional group, and by considering the dummy variable, then, three impacts are composing the institutional group. The domain expert is invited to conduct his own assessment for all groups of variables with respect to the conditions related to the city of Jeddah. After completing the process of pair comparisons, the individual weight assignment is added and the Impact Identification Coefficient (IIC) is calculated. IIC is estimated by adding the individual impact weight assignment divided by the total sum of all the impacts. To validate the sum result, the following formula is used as follows:

$$
S U M=\frac{N(N-1)}{2}
$$

Where

$\mathrm{N}$ is the number of impacts, which is (3) in our case. IIC total should be 1 .

$$
\text { SUM }=\frac{3(3-1)}{2}=3
$$

Table (1) represents the importance weight assignment for the input variables of institutional group. The qualitative scale used to determine impact magnitude ranges from (0) to (100) points. Magnitude and direction are simultaneous. For example, if the development of a project had resulted in a loss of (20\%) of coral reefs community, this could be considered very positive, while, if the loss of coral reefs is around (80\%), then this could be considered very negative. The scale used for this type of input variables is a reversed scale in the sense that the higher the score is close to (100), the impact is considered very negative and the lower the score is close to zero, then the impact is 
considered very positive. Other type of variables is using the normal scale to determine the score of magnitude. For example, if the management of coastal resort project had hired $(80 \%)$ of project employment from the local market, then this could be considered very positive, while, if the local hired employment did not exceed (10\%), then this could be considered very negative. There are two common linguistic scales of values or terms used in EIA studies to assess every input variable,

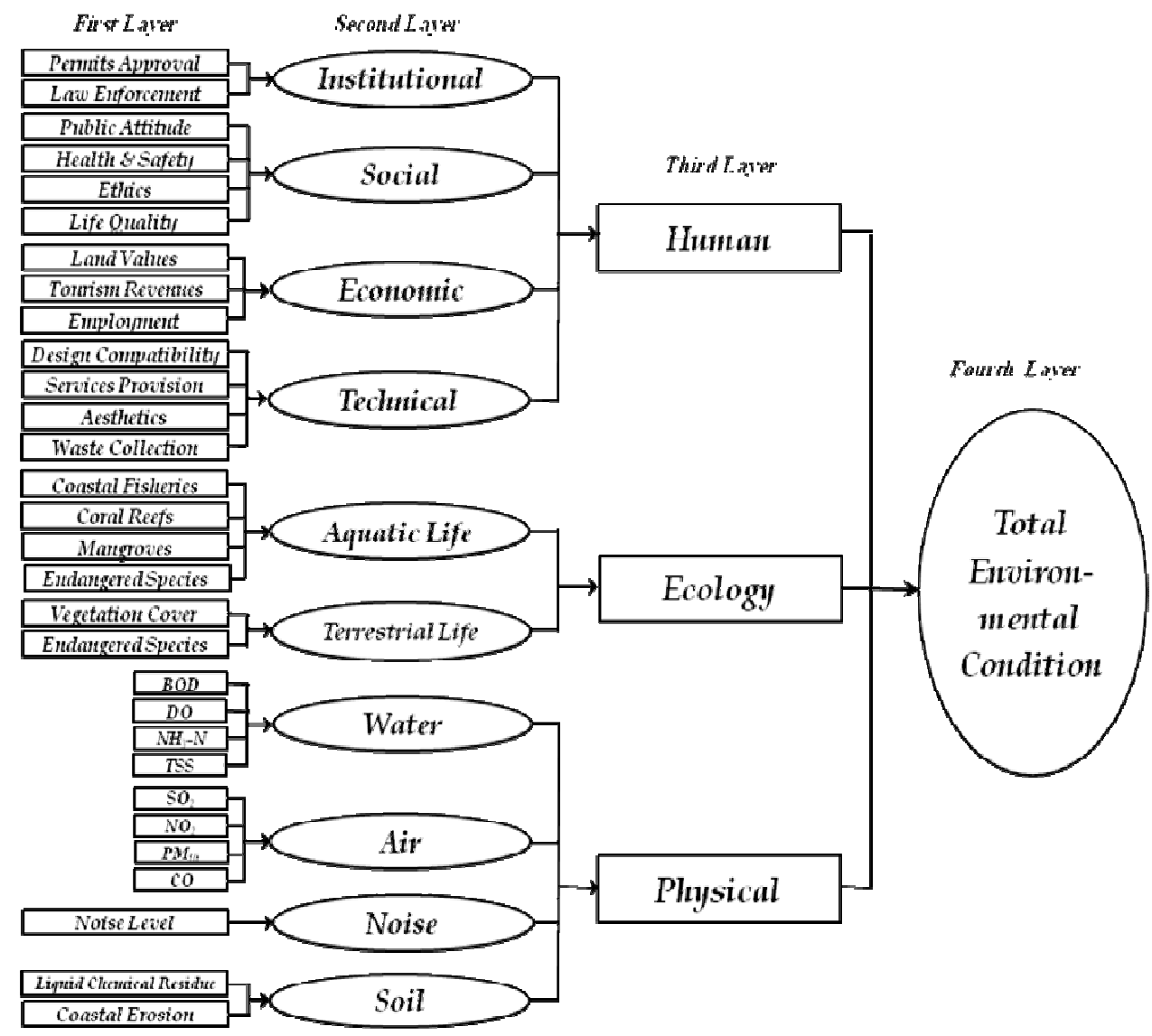

Figure (1) Impact Decision Tree (IDT) for Jeddah Case Study

Table (1) Importance Weighting of the Input Variables of the Institutional Group

\begin{tabular}{|c|c|c|c|c|c|c|}
\hline No. & Impact & \multicolumn{3}{|c|}{ Weight Assignment } & Total & Importance \\
\hline 1 & Permits Approval & 0.50 & 1.00 & & 1.50 & 0.50 \\
\hline 2 & Law Enforcement & 0.50 & & 1.00 & 1.50 & 0.50 \\
\hline \multirow[t]{2}{*}{3} & Dummy & & 0.00 & 0.00 & 0.00 & 0.00 \\
\hline & \multicolumn{4}{|c|}{ SUM } & 3.00 & 1.00 \\
\hline
\end{tabular}


five linguistic values scale, and seven linguistic values scale. The five values scale was adopted as the seven values scale is considered too cumbersome for assessors. The adopted linguistic values scale is Very Negative (VN), Negative (N), Neutral, Positive (P) and Very Positive (VP). Figures (2) and (3) are representing the normal and reversed scale using the five linguistic values.

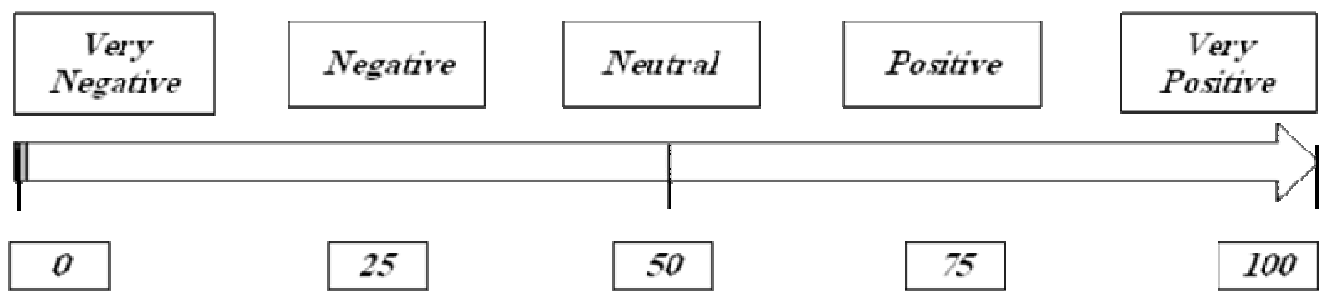

Figure (2) Normal Scale Using Five Linguistic Values

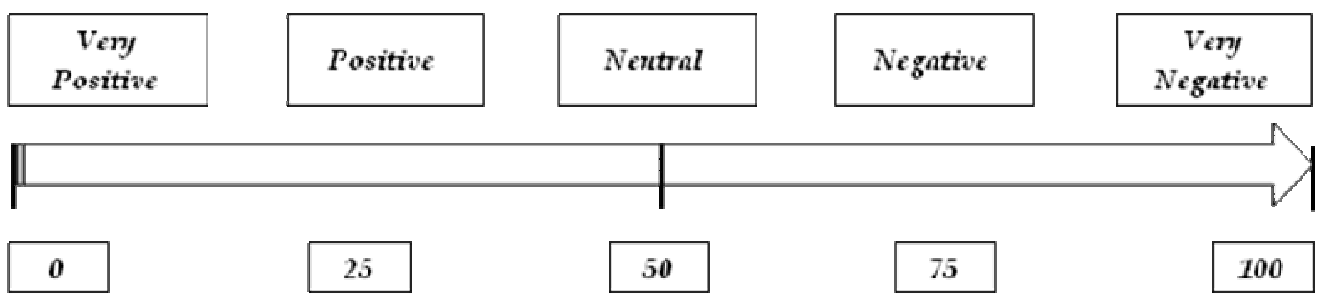

Figure (3) Reversed Scale Using Five Linguistic Values

Every input variable has a specific range of magnitude corresponding to every linguistic value. The extraction of such knowledge had been conducted through the domain expert who is asked to define the magnitude range corresponding to every linguistic value for each input variable. Table (2) represents each impact magnitude range corresponding to every linguistic value. The quantitative base variables have only three linguistic values of Negative, Neutral and Positive since uncertainty is reduced by the regulation thresholds. The domain expert was asked to conduct his assessment concerning the magnitude values based on the magnitude ranges of the five linguistic values scale with respect to the conditions related to the city of Jeddah. Once importance weighting and magnitude of each input variable is identified, then the crisp input value of each input variable could be calculated by multiplying importance weight by magnitude value for each input variable. As far as the quantitative parameters of air and water quality impacts are concerned, the information of the annual average readings of air quality parameters for the year 2009 are taken from PME, and the information of the annual average readings of water quality parameters discharged from the outfalls of the sewage treatment stations for the year 2009 are taken from the Ministry of Water And Electricity. Table (3) represents the crisp values for all input variables with respect to the conditions related to the city of Jeddah. The result of multiplying every input variable importance by its magnitude is the quantified evaluation of significance for each variable and is considered as the crisp value, which shall be fuzzified in the knowledge base. 
The definitions of Membership Functions (MBFs) using linguistic variables and the operation of the fuzzy sets are carried out according to the fuzzy logic principles in the light of Shepard (2005), An et. al (2006), Shull (2006), and Mathworks (2008). For MBFs, Every Input variable and indicator has several linguistic values and each one is defined by a MBF. The MBFs used are represented by three linguistic values Bad, Critical and Good.

Table (2) Magnitude Ranges Corresponding to Every Linguistic Value

\begin{tabular}{|c|c|c|c|c|c|c|c|c|c|c|c|}
\hline \multirow{2}{*}{$\begin{array}{c}\text { No. } \\
1 \\
\end{array}$} & \multirow{2}{*}{$\begin{array}{l}\text { Input Variable } \\
\text { Permits Approval }\end{array}$} & \multicolumn{2}{|c|}{$\mathbf{V N}$} & \multicolumn{2}{|c|}{$\mathbf{N}$} & \multicolumn{2}{|c|}{ Neutral } & \multicolumn{2}{|c|}{$\mathbf{P}$} & \multicolumn{2}{|c|}{ VP } \\
\hline & & 70 & 100 & 40 & 70 & 30 & 40 & 15 & 30 & 0 & 15 \\
\hline 2 & Law Enforcement & 0 & 45 & 45 & 70 & 70 & 80 & 80 & 90 & 90 & 100 \\
\hline 3 & Health \& Safety & 60 & 100 & 30 & 60 & 20 & 30 & 10 & 20 & 0 & 10 \\
\hline 4 & Public Attitude & 0 & 15 & 15 & 50 & 50 & 60 & 60 & 80 & 80 & 100 \\
\hline 5 & Ethics & 65 & 100 & 50 & 65 & 25 & 50 & 10 & 25 & 0 & 10 \\
\hline 6 & Quality of Life & 0 & 25 & 25 & 55 & 55 & 65 & 65 & 75 & 75 & 100 \\
\hline 7 & Land Values & 70 & 100 & 50 & 70 & 40 & 50 & 20 & 40 & 0 & 20 \\
\hline 8 & Revenues & 0 & 40 & 40 & 60 & 60 & 70 & 70 & 85 & 85 & 100 \\
\hline 9 & Employment & 0 & 15 & 15 & 35 & 35 & 55 & 55 & 70 & 70 & 100 \\
\hline 10 & Design Compatibility & 0 & 20 & 20 & 45 & 45 & 75 & 75 & 90 & 90 & 100 \\
\hline 11 & Services Provision & 0 & 25 & 25 & 50 & 50 & 80 & 80 & 90 & 90 & 100 \\
\hline 12 & Aesthetics & 0 & 20 & 20 & 45 & 45 & 75 & 75 & 90 & 90 & 100 \\
\hline 13 & Waste Collection & 0 & 25 & 25 & 50 & 50 & 80 & 80 & 90 & 90 & 100 \\
\hline 14 & Vegetation Cover & 70 & 100 & 55 & 70 & 40 & 55 & 20 & 40 & 0 & 20 \\
\hline 15 & $\begin{array}{c}\text { Endangered Species } \\
\text { (Terrestrial) }\end{array}$ & 50 & 100 & 35 & 50 & 20 & 35 & 10 & 20 & 0 & 10 \\
\hline 16 & Coral Reefs & 50 & 100 & 35 & 50 & 20 & 35 & 10 & 20 & 0 & 10 \\
\hline 17 & Coastal Fisheries & 60 & 100 & 40 & 60 & 30 & 40 & 15 & 30 & 0 & 15 \\
\hline 18 & Mangroves & 60 & 100 & 45 & 60 & 35 & 45 & 20 & 35 & 0 & 20 \\
\hline 19 & $\begin{array}{c}\text { Endangered Species } \\
\text { (Aquatic) }\end{array}$ & 50 & 100 & 35 & 50 & 20 & 35 & 10 & 20 & 0 & 10 \\
\hline 20 & $\mathrm{SO}_{2}(\mathrm{ppm})$ & & & 85 & 165 & 80 & 85 & 0 & 80 & & \\
\hline 21 & $\mathrm{NO}_{2}(\mathrm{ppm})$ & & & 100 & 195 & 95 & 100 & 0 & 95 & & \\
\hline 22 & $\mathrm{PM}_{10}\left(\mathrm{mg} / \mathrm{m}^{3}\right)$ & & & 80 & 156 & 76 & 80 & 0 & 76 & & \\
\hline 23 & $\mathrm{CO}\left(\mathrm{mg} / \mathrm{m}^{3}\right)$ & & & 10 & 19.5 & 9.5 & 10 & 0 & 9.5 & & \\
\hline 24 & $\mathrm{DO}(\mathrm{mg} / \mathrm{l})$ & & & 0.0 & 7.5 & 7.5 & 8.0 & 8.0 & 15.5 & & \\
\hline 25 & $\mathrm{NH}_{3}-\mathrm{N}(\mathrm{mg} / \mathrm{l})$ & & & 1 & 1.95 & 0.95 & 1 & 0 & 0.95 & & \\
\hline
\end{tabular}




\begin{tabular}{|c|c|c|c|c|c|c|c|c|c|c|c|}
\hline 26 & TSS (mg/l) & & & 15 & 29 & 14 & 15 & 0 & 14 & & \\
\hline 27 & BOD (mg/l) & & & 25 & 49 & 23.75 & 25 & 0 & 23.75 & & \\
\hline 28 & Noise Levels & 75 & 100 & 60 & 75 & 50 & 60 & 30 & 50 & 0 & 30 \\
\hline 29 & $\begin{array}{c}\text { Liquid Chemical } \\
\text { Residue }\end{array}$ & 70 & 100 & 40 & 70 & 25 & 40 & 15 & 25 & 0 & 15 \\
\hline 30 & Coastal Erosion & 70 & 100 & 50 & 70 & 35 & 50 & 20 & 35 & 0 & 20 \\
\hline
\end{tabular}

Table (3) Magnitude Values, Importance Weights and Crisp Input Values of all Input Variables with Respect to the Conditions Related to the City of Jeddah

\begin{tabular}{|c|c|c|c|c|}
\hline No. & Input Variable & Magnitude & Importance & Crisp Input Value \\
\hline 1 & Permits Approval & 80 & 0.50 & 40.00 \\
\hline 2 & Law Enforcement & 65 & 0.50 & 32.50 \\
\hline 3 & Health \& Safety & 75 & 0.33 & 24.75 \\
\hline 4 & Public Attitude & 50 & 0.21 & 10.50 \\
\hline 5 & Ethics & 75 & 0.21 & 15.75 \\
\hline 6 & Quality of Life & 70 & 0.26 & 18.20 \\
\hline 7 & Land Values & 60 & 0.31 & 18.60 \\
\hline 8 & Revenues & 65 & 0.33 & 21.45 \\
\hline 9 & Employment & 60 & 0.36 & 21.60 \\
\hline 10 & Design Compatibility & 60 & 0.23 & 13.80 \\
\hline 11 & Services Provision & 80 & 0.29 & 23.20 \\
\hline 12 & Aesthetics & 75 & 0.20 & 15.00 \\
\hline 13 & Waste Collection & 70 & 0.30 & 21.00 \\
\hline 14 & Vegetation Cover & 50 & 0.43 & 21.50 \\
\hline 15 & $\begin{array}{c}\text { Endangered Species } \\
\text { (Terrestrial) }\end{array}$ & 90 & 0.57 & 51.30 \\
\hline 16 & Coral Reefs & 90 & 0.29 & 26.10 \\
\hline 17 & Coastal Fisheries & 70 & 0.18 & 12.60 \\
\hline 18 & Mangroves & 90 & 0.26 & 23.40 \\
\hline 19 & $\begin{array}{c}\text { Endangered Species } \\
\text { (Aquatic) }\end{array}$ & 90 & 0.28 & 25.20 \\
\hline 20 & Noise Levels & 25 & 1.00 & 25.00 \\
\hline 21 & Liquid Chemical Residue & 10 & 0.57 & 5.70 \\
\hline 22 & Coastal Erosion & 40 & 0.43 & 17.20 \\
\hline 23 & $\mathrm{DO}(\mathrm{mg} / \mathrm{l})$ & 3.72 & ---- & 3.72 \\
\hline 24 & $\mathrm{BOD}(\mathrm{mg} / \mathrm{l})$ & 41.04 & ---- & 41.04 \\
\hline
\end{tabular}




\begin{tabular}{|c|c|c|c|c|}
\hline 25 & $\mathrm{TSS}(\mathrm{mg} / \mathrm{l})$ & 27.50 & ---- & 27.50 \\
\hline 26 & $\mathrm{NH}_{3}-\mathrm{N}(\mathrm{mg} / \mathrm{l})$ & 0.83 & ---- & 0.83 \\
\hline 27 & $\mathrm{SO}_{2}(\mathrm{ppm})$ & 34.58 & ---- & 34.58 \\
\hline 28 & $\mathrm{NO}_{2}(\mathrm{ppm})$ & 63.92 & ---- & 63.92 \\
\hline 29 & $\mathrm{PM}_{10}\left(\mathrm{mg} / \mathrm{m}^{3}\right)$ & 65.5 & ---- & 65.50 \\
\hline 30 & $\mathrm{CO}\left(\mathrm{mg} / \mathrm{m}^{3}\right)$ & 5.11 & ---- & 5.11 \\
\hline
\end{tabular}

Therefore, each crisp value obtained from the studied input variable is correlated to the established linguistic values, which the basis varied from zero to 100 . MBFs are represented graphically by different shapes. The Gaussian shape is selected for the developed model. Two reasons for this selection (Shepard, 2005): first, Gaussian MBFs are extensively used in EIA to represent the meaning of measured components in the existing environment and changes predicted under different alternatives. Secondly, they represent real life situations, as they are non zero at all points. The parameters utilized to draw the MFC curve are standard deviation and centre for the Gaussian curve. To define these parameters, the domain expert was asked to define the magnitude ranges for every input and output variable corresponding to the three linguistic values of Bad, Critical and Good. After the definition of these ranges, the calculation of the parameters of the curve was computed using Microsoft Excel. Following the sequence, the rules that operate the relationships among the variables have to be established. The methodology used in this research study to develop the rules is the knowledge extraction through domain expert. The knowledge of rules extracted from the domain expert is stored in the output variables and are considered as the fuzzy knowledge bases. In each rule block of fuzzy knowledge base, the composition of the input variables and indicators consist of two main parts: If (antecedent) and Then (consequent). While the If part of the rule describes the situation for which it is designed, the Then part describes the action of the fuzzy system in this situation. There are 14 rule blocks of fuzzy knowledge bases that operate the relationships among the input variables and indicators. In order to operate the fuzzy sets, several meetings had been held with the domain expert to extract the knowledge of rules. The conditions established by the rule blocks were assumed by the domain expert to be of the restriction type with the And sets combination. In addition, means that we have an intersection of two sets. The knowledge base rule for water quality can be exemplified. The parameters of water quality are DO, BOD, TSS, and $\mathrm{NH}_{3}-\mathrm{N}$. According to the knowledge of the domain expert, DO and BOD are complements to each other and should have the same condition whether Good or Bad. Therefore, any contradicting relationship between them in the rule set does not reflect real life conditions. Moreover, DO is a determinant parameter that affects the condition of the resulting water quality in the sense that DO reflects the level of Oxygen in water, therefore, if Oxygen level is $\mathrm{Bad}$, then this means that aquatic and marine life is exposed to death hazards and vice versa. Accordingly, the total number of rules representing the relationships among water quality parameters is (37) rules. A sample of the rules created for the water quality knowledge base is shown in Table (4). The results of the operation in these knowledge base rule blocks are represented by linguistic values, which need to be converted back to a crisp number. This resultant number represents the existing environmental condition or the projected future 
conditions of the alternative. The process of representing a consequent fuzzy set as a crisp number is called defuzzification. Thus, each set of input variables, operated in a rule block, results in two outputs. One with fuzzy values, which will feed a new input for the next set and other defuzzificated value with crisp number. These two outputs shall allow a better comprehension by the decision makers to visualize and interpret each result. The value of the consequent set can be determined by several methods.

Table (4) Sample of Water Quality Knowledge Base Rules

\begin{tabular}{|c|c|c|c|c|c|c|c|c|c|}
\hline No. & DO & Op* & $\mathrm{NH}_{3}-\mathrm{N}$ & Op* & TSS & Op* & BOD & THEN & $\begin{array}{c}\text { Water } \\
\text { Quality }\end{array}$ \\
\hline 1 & Bad & ---- & ---- & ---- & ---- & ---- & ---- & THEN & Bad \\
\hline 2 & Critical & AND & Bad & AND & Good & AND & Critical & THEN & Critical \\
\hline 3 & Critical & AND & Critical & AND & Good & AND & Critical & THEN & Critical \\
\hline 4 & Good & AND & Bad & AND & Critical & AND & Good & THEN & Good \\
\hline 5 & Good & AND & Critical & AND & Critical & AND & Good & THEN & Good \\
\hline 6 & Critical & AND & Good & AND & Critical & AND & Good & THEN & Critical \\
\hline 7 & Good & AND & Good & AND & Critical & AND & Good & THEN & Good \\
\hline 8 & Critical & AND & Bad & AND & Good & AND & Good & THEN & Good \\
\hline 9 & Good & AND & Bad & AND & Good & AND & Good & THEN & Good \\
\hline 10 & Critical & AND & Good & AND & Bad & AND & Good & THEN & Critical \\
\hline 11 & Good & AND & Good & AND & Bad & AND & Good & THEN & Good \\
\hline
\end{tabular}

Op* = Operator

According to Shepard (2005), the center of gravity is suitable for the semantics inherent in an EIA and makes a good default that will be appropriate most of the time. This defuzzified crisp value is considered as the Decision Making Coefficient (DMC) for the EIA system development. This DMC value represents the magnitude of relative severity on the environment. The higher the DMC magnitudes, the change to environment condition tends to be bad and vice versa. Concerning the baseline for the existing conditions of the city of Jeddah, the defuzzified value resulted from the inputted crisp values which were based on the assessment of the domain expert for importance weights and magnitude values for all input variables was (56.04). This defuzzified value is called Jeddah DMC and was calculated by simulink of Matlab software. Jeddah DMC is considered as a standard baseline or benchmark from which any project alternative is compared and evaluated.

\section{II-3- Implementation}

The implementation of the proposed DSS is conducted for developing the existing baseline conditions for the city of Jeddah. As explained previously, an existing baseline conditions were established for the city of Jeddah to have a standard against which 
various project alternatives are compared and evaluated. For this reason, the domain expert conducted his assessment and the resultant DMC for the city of Jeddah is (56.04) and the fuzzy value is Critical. The procedure of computation in the impact decision tree is hierarchical and the various weights and collective (or accumulative) effects are aggregated to each output variable according to the inference of a rule block that defines the result. Figure (4) represents the IDT for Jeddah existing baseline conditions with the resulting fuzzy values and DMCs for all output variables.

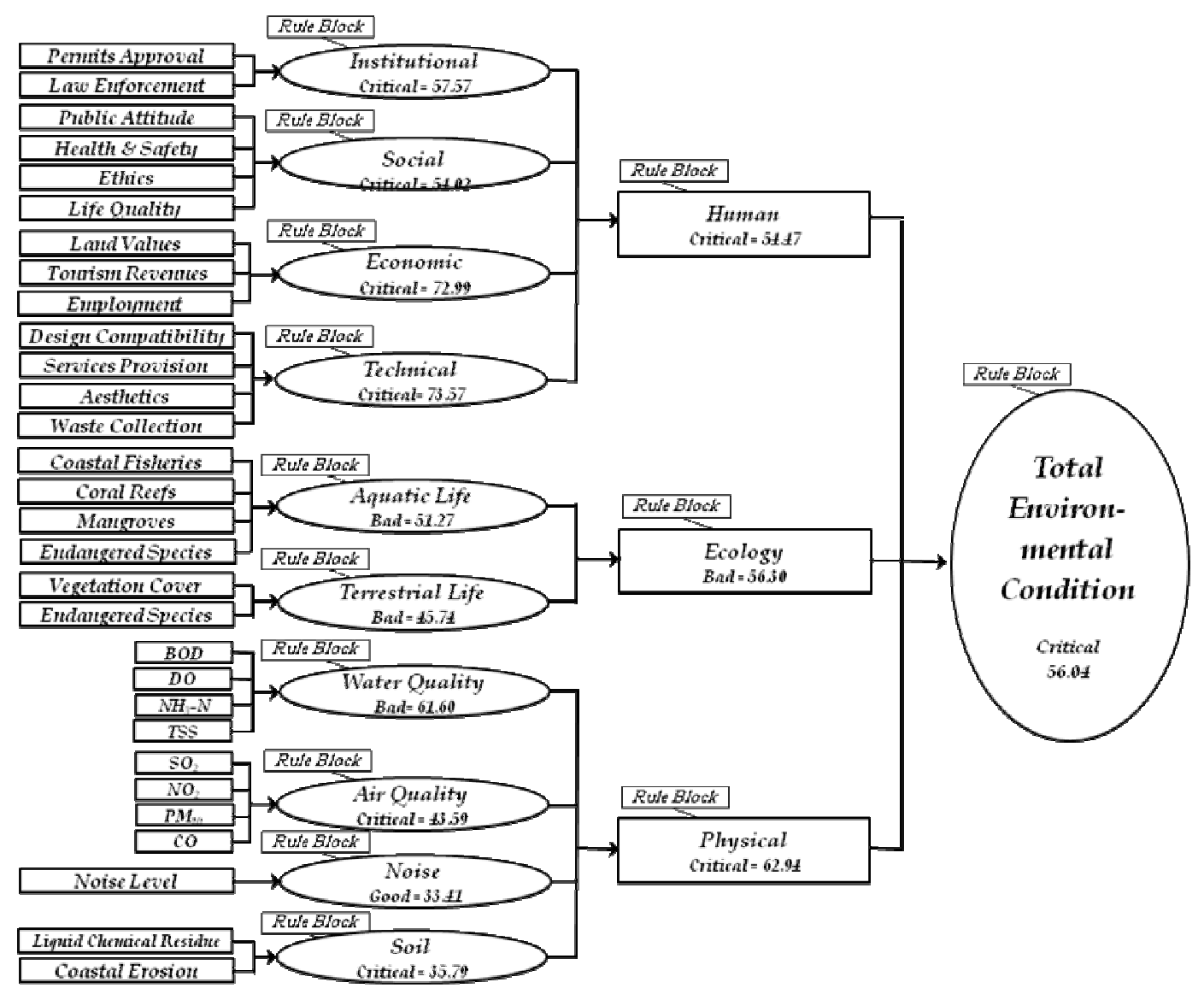

Figure (4) IDT for Jeddah Existing Baseline Conditions with the Resulting Fuzzy Values and DMCs

According to the assessment of the domain expert, the resulting DMC for the Aquatic conditions for the city of Jeddah is (51.27), which represents Bad existing quality condition. This is understandable in the sense that dredging and filling operations of the uncontrolled coastal resort development projects along the Red Sea coast of Jeddah city had led to severe deterioration of some unique natural resources of Aquatic life. For example, a recent marine survey conducted in 2004 on the coral reef communities of the Red Sea revealed that around $70 \%$ were destroyed and the remaining were either defected or exposed to destruction (AL-Kenani 2008). 
Moreover, this development adversely affected the existing mangroves communities, coastal fisheries, and endangered species. A firm monitoring by PME staff should be exercised to eliminate these exercises.

The resulting DMC for the Terrestrial conditions for the city of Jeddah is (45.74), which represents Critical existing quality condition in the sense that the uncontrolled coastal resort development altered the coastline morphology and reduced the land habitat for many bird species.

The DMC for Institutional conditions is (57.57), which represents Critical existing quality condition. Several remarks are outlined to take the necessary actions by PME authority to improve the current situation as follows:

- Permits Approval: Long procedures and time delay due to multi government agencies involved in the decision making of EIA permits approval, shortage of staff and lack of technical experience of the staff in the field of EIA.

- Law Enforcement: Firm implementation of the environmental laws and regulations shall assist in the sustainable development of the city and hence attracts local and foreign tourists.

The DMC for Technical conditions is (73.75), which represents Critical existing quality condition. Several remarks are outlined to be considered by investors and the various government agencies to improve the current situation as follows:

- Design Compatibility: Societal values considerations are very important to the local residents, which makes it a family oriented type of tourism and a distinctive feature of tourism in the Middle East region.

- Services provision: Availability of electricity, water and sewage treatment services are essential to control water pollution as well as reduce rental prices of residential units in coastal resort projects. According to Mohorjy and Aburiziza (1997), in many areas within the city of Jeddah, the absence of a proper sewage system has caused the groundwater table to rise sharply and reach the surface, creating pools of wastewater, which are a breeding ground for mosquitoes and other insects. The rise in groundwater also has affected foundations and walls of buildings and pavements. In some areas, this has affected property and land values. Proper collection and treatment of wastewater in Jeddah is necessary to control pollution, which is increasing with time. Less than $30 \%$ of the Jeddah area is served by public sewers. The other 70\% uses cesspools to dispose of residential and commercial wastewater. Septic sewage is trucked from the cesspools and dumped in several locations around the city.

The DMC for Water Quality conditions is (61.60), which represents Bad existing quality condition. It has been observed that city sea water in different areas is polluted due to the direct discharge of partly treated and raw sewage to the sea. A firm monitoring and control by PME staff is required to eliminate this situation so as not to defect public health of community members as well as to improve the aesthetic values of the city sea frontier.

The DMC for Environment conditions is (56.04), which represents Critical existing quality condition. The resultant DMC for the city of Jeddah is a standard against which various projected future conditions from project alternatives are compared and evaluated. 


\section{VI- CONCLUSIONS}

The present study intends to contribute for the improvement of the current assessment processes of environmental impacts in the city of Jeddah by establishing a base index for environmental assessment of coastal resort projects along Red Sea coast of the city of Jeddah using fuzzy logic for the evaluation and comparison of future project alternatives and proposals. The IDT that uses a fuzzy logic offer a practical solution to the evaluation of environmental impacts that express the quantitative threshold and represent qualitative values inherited in EIA decision process. The implementation indicates that the DMC for the city of Jeddah is (56.04), which represents Critical existing quality condition. This method contributes to support decision makers in public and private sectors to foresee more clearly the environmental impacts of future project alternatives.

\section{V- REFERENCES}

1- Ahmad, Y., and Sammy, G. (1985) Guidelines to Environmental Impact Assessment in Developing Countries, $2^{\text {nd }}$ Ed., Hodder and Stoughton, London.

2- Al-Kenani, A.A., Okaz Newspaper, No. 15461, 25 December 2008.

3- An, M., Lin, W., and Stirling, A. (2006) Fuzzy Reasoning Based Approach to Qualitative Railway Risk Assessment, Journal of Rail and Rapid Transit, Vol. 220, part F.

4- Boclin, A., and Mello, R. (2005) A Decision Support Method for Environmental Impact Assessment using a Fuzzy Logic Approach, Ecological Economics, Vol. 58, pp 170-181.

5- Keeney, R.L., and Robilliard, G.A. (1976) Assessing and Evaluating Environmental Impacts at Proposed Nuclear Power Plant Sites, Journal of Environmental Economics and Management, Vol. 4, pp 153-166.

6- Liu, K., Haung, S., and Liang, H. (2007) A Qualitative Decision Support for Environmental Impact Assessment using Fuzzy Logic, Environmental Information Archives, Vol. 5, pp 469-479.

7- Math Works, Inc. (2007) Matrix Laboratory software, MATLAB, User's Manual, The Math Works, Inc,.

8- Mohorjy, A. (1997) Importance Weighting of Impacts in Environmental Impact Studies, Journal of Environmental Engineering, Vol. 123, No. 12, pp 1261-1267.

9- Mohorjy, A., and Aburizaiza, O. (1997) Impact Assessment of an Improper Effluent Control System: A Delphi Approach, Environmental Impact Assessment Review, Vol.17, No. 3, pp 205-217.

10- PME (2003) The Regulations of the Overall System of the Environment in Saudi Arabia, Jeddah: PME.

11- Shepard, R.B. (2005) Quantifying Environmental Impact Assessment Using Fuzzy Logic, Springer, New York.

12- Shull, N.D.P. (2006) Project Evaluation Using Fuzzy Logic and Risk Analysis Techniques, Master of Science, Industrial Engineering Department, University of Pnerto Rico. 
13- Tsamboulas, D., and Mikroudis, G. (2000) EFECT - evaluation framework of environmental impacts and costs of transport initiatives Transportation Research, Part D 5, pp 283-303.

14- UNEP (2002) Environmental Impact Assessment, $2^{\text {nd }}$ Ed., Training Resource Manual, US

\section{تطوير مؤثر قاعدة للتقويم البيئي لمشروعات المنتجعات الساحلية على طول ساحل البحر الأحمر بمدينة جدة البنات}

قرار الموافقة على دراسات تقويم الأثر البيئي معقد إلى حد كبير بسبب عامل الثلك وعدم اليقين عن

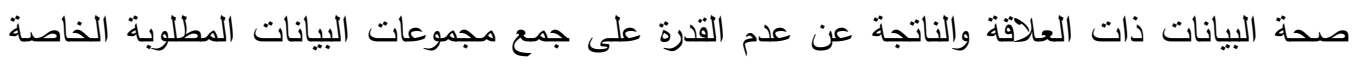

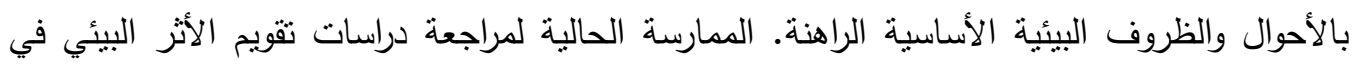

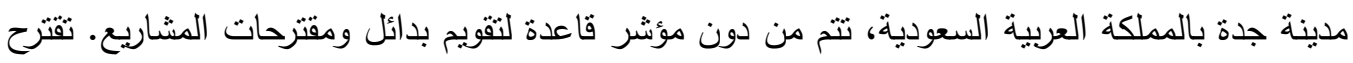

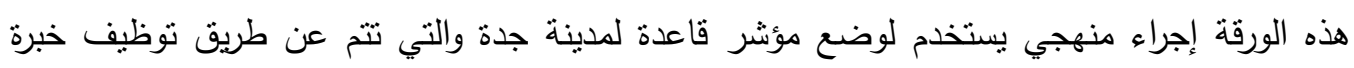

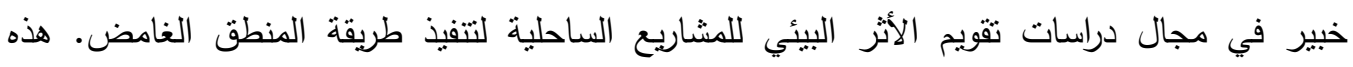

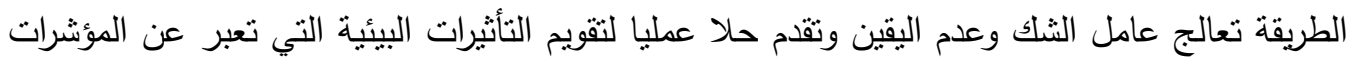

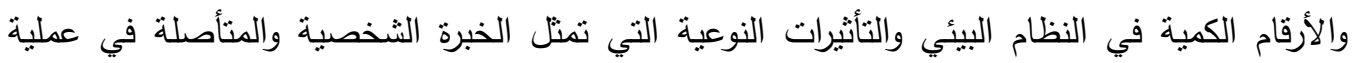

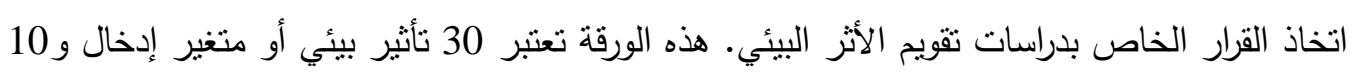

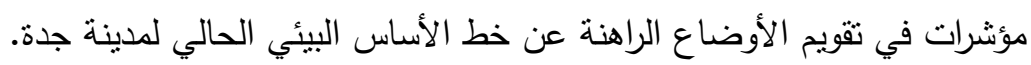

